\title{
Effect of temperature on polarization reversal of strontium-doped lead zirconate titanate (PSZT) ceramics
}

\author{
N N WATHORE* ${ }^{*}$ C M LONKAR and D K KHARAT \\ DRDO Centre for Piezoceramics and Devices, Armament Research and Development Establishment, Pune 400 021, India
}

MS received 11 August 2009; revised 5 March 2010

\begin{abstract}
The effect of temperature on polarization reversal of strontium-doped lead zirconate titanate ceramics was studied. The piezoelectric properties viz. dielectric constant and piezoelectric coupling coefficient, were used for polarization reversal characteristic. These properties and apparent coercive field were measured during polarization reversal at different temperatures. Results indicated that at higher temperature apparent coercive field decreased. Polarization reversal and further polarization reversal was quite asymmetric. After polarization reversal, dielectric constant was found to increase at all temperatures while piezoelectric coupling coefficient increased above the temperature of polarization. The trend shown by dielectric constant indicates that at $25^{\circ} \mathrm{C}, 1.5 \mathrm{kV} / \mathrm{mm}$ field can be applied safely to this material without much compromising the properties. D.c. field of $3.0 \mathrm{kV} / \mathrm{mm}$ and $100^{\circ} \mathrm{C}$ temperature can be predicted as poling parameters from their effect on $k_{\mathrm{p}}$. Apparent coercive field has shown non-linear relationship with temperature. It was of exponential decay type.
\end{abstract}

Keywords. Polarization reversal; dielectric constant; coupling coefficient; apparent coercive field; poling temperature.

\section{Introduction}

Lead strontium zirconate titanate (PSZT) ferroelectric ceramics are widely used to tailor ferroelectric properties such as switching field and hysteresis (Yongjian et al 2001). The polarization of ferroelectric ceramics due to an electric field can be reversed by applying an opposite field. In polarization reversal (PR), switching occurs as a result of voltage applied in the opposite direction (Nowotny 1992). Polarization reversal is accomplished by rotation of dipoles in the ferroelectric ceramics (Wang et al 1988). Reversal of domain produces remarkable change of strain in ferroelectric ceramics (Wenfung et al 2006).

The behaviour of the electrical field in the opposite direction is considerably different and more complex (Jaffe et al 1971). The work on the effect of PR on piezoelectric properties of ferroelectric ceramics was carried out by many researchers. Merz (1956) had carried out a beautiful piece of work on polarization reversal on ferroelectric ceramics, barium titanate $\left(\mathrm{BaTiO}_{3}\right)$ and concluded that PR is accomplished by the nucleation of antiparallel domains and their growth as a domain wall motion. Polarization reversal of lead lanthanum zirconate titanate using a piezoelectric property coupling coefficient $\left(k_{\mathrm{p}}\right)$ was analysed at room temperature (Okazaki and Nagata 1973), but effect of temperature on PR was not considered. In late 1990, the effect of temperature on PR (Dimmler et al 1987) of domain in ferroelec-

*Author for correspondence (nnwathore@ hotmail.com) tric potassium nitrate $\left(\mathrm{KNO}_{3}\right)$ was determined. In the present study, PSZT ferroelectric ceramic was selected for the study of PR and effect of temperature on dielectric constant $\left(K_{3}^{T}\right)$ and $k_{\mathrm{p}}$ was examined. The effect of temperature on apparent coercive field was determined. Also observed was further polarization reversal (FPR) on $k_{\mathrm{p}}$.

\section{Experimental}

The composition selected for the study was $\mathrm{Pb}_{0.94} \mathrm{Sr}_{0.06}\left(\mathrm{Zr}_{0.53}, \mathrm{Ti}_{0.47}\right)$. The ferroelectric ceramics were prepared from powders of $\mathrm{SrCO}_{3}, \mathrm{PbO}, \mathrm{ZrO}_{2}$ and $\mathrm{TiO}_{2}$. It was processed by mixed oxide route. The powders were weighed and mixed with zirconia grinding media and distilled water for $24 \mathrm{~h}$ in roller mill. Calcination of the powder was carried out at $1000^{\circ} \mathrm{C}$ for $4 \mathrm{~h}$. The powder was pressed into discs of $10 \mathrm{~mm}$ in diameter and $1 \mathrm{~mm}$ in thickness. The discs were sintered between $1260^{\circ} \mathrm{C}$ and $1300^{\circ} \mathrm{C}$ for $1 \mathrm{~h}$ in a closed alumina crucible. Sintered discs were lapped for smooth surface and silver electroded for ferroelectric measurement. The sample was poled by applying d.c. electrical field, $3 \mathrm{kV} / \mathrm{mm}$, in silicon oil bath at temperature, $80^{\circ} \mathrm{C}$ for 30 min. D.C. electrical field was applied by high voltage power supply (Brandenburg make, USA).

The effect of temperature on PR was carried out at different temperature ranges, $25-120^{\circ} \mathrm{C}$, by applying electrical field in the opposite direction to the original polarization. The PR field was applied in increasing increments of $0.5 \mathrm{kV} / \mathrm{mm}$ maintained for 2 min across the ferroelectric ceramics at different temperatures. Polarity of component was noted and 
$d_{33}$ was measured by using $d_{33}$ meter (make Berlincourt). The direction of the polarization was marked on the ferroelectric ceramics. Capacitance $(C)$, resonance frequency $\left(f_{\mathrm{r}}\right)$ and anti-resonance frequency $\left(f_{\mathrm{a}}\right)$ were measured using HIOKI 3532 - 50 LCR HITESTER (Japan). $K_{3}^{T}$ and $k_{\mathrm{p}}$ were calculated using standard empirical relations. Further reversal to original polarization was carried out by applying electrical field to original poling direction by the same method as applied to the PR.

\section{Results and discussion}

Figure 1 represents the effect of temperature on polarization reversal on $K_{3}^{T}$ of PSZT. It was observed at all temperatures that as the polarization reversal field is applied, $K_{3}^{T}$ initially decreases and acquires a minimum value and again increases. The $K_{3}^{T}$ minima was observed at a lower polarization reversal field as the temperature was increased. At $25^{\circ} \mathrm{C}$, the minima for $K_{3}^{T}$ was observed at $2.5 \mathrm{kV} / \mathrm{mm}$. At the same temperature, up to $2.0 \mathrm{kV} / \mathrm{mm}$, decrease in $K_{3}^{T}$ was very slow but after that it decreased very sharply. It can be concluded that this material can be used safely at $1.5 \mathrm{kV} / \mathrm{mm}$ at $25^{\circ} \mathrm{C}$ without much compromising the properties. As the temperature increased the response for polarization reversal field was changed as compared to the $25^{\circ} \mathrm{C}$ temperature. At increased temperature the decrease in $K_{3}^{T}$ was very sharp. The $K_{3}^{T}$ minima was observed at $1.5 \mathrm{kV} / \mathrm{mm}, 1.25 \mathrm{kV} / \mathrm{mm}$ and $1 \mathrm{kV} / \mathrm{mm}$ for temperatures $80^{\circ} \mathrm{C}, 100^{\circ} \mathrm{C}$ and $120^{\circ} \mathrm{C}$, respectively. At temperature, $120^{\circ} \mathrm{C}$, as the polarization reversal field increased beyond $2.5 \mathrm{kV} / \mathrm{mm}$, there was not much increment in the $K_{3}^{T}$. From this trend, $2.5 \mathrm{kV} / \mathrm{mm}$ at $120^{\circ} \mathrm{C}$ can be considered as a poling field for this composition.

Figure 2 represents the effect of temperature on polarization reversal of PSZT. $k_{\mathrm{p}}$ alone can show the strength of piezoelectric effect. The upper side of the abscissa is the original poling direction. From different curves it was observed that $k_{\mathrm{p}}$ decreased very slowly from it and reversed

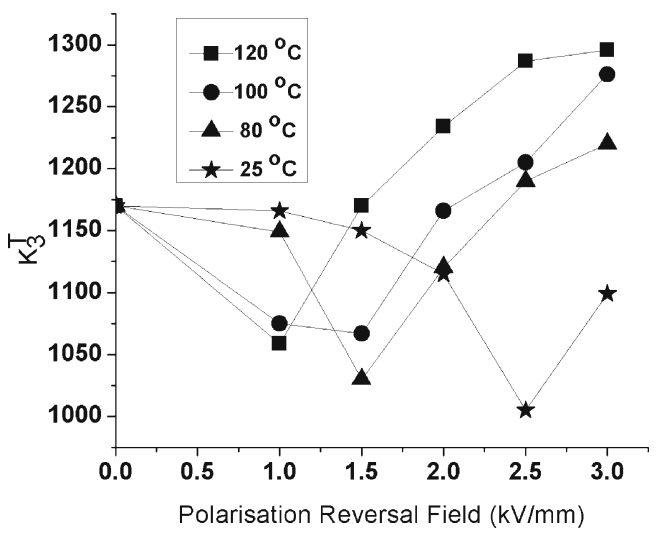

Figure 1. Effect of temperature on $K_{3}^{T}$ of polarization reversal.

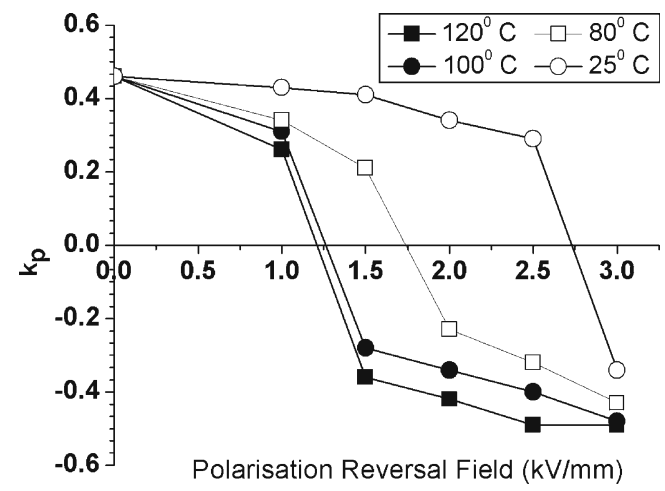

Figure 2. Effect of temperature on $k_{\mathrm{p}}$ of polarization reversal.

up to $1 \mathrm{kV} / \mathrm{mm}$ polarization reversal field. After that polarization reversal field, $k_{\mathrm{p}}$, decreased drastically and on passing through the abscissa it increased drastically in the opposite direction up to $1.5 \mathrm{kV} / \mathrm{mm}$ polarization reversal field. This drastic reversal may be due to reversal of dipoles along easy axis of poling, i.e. $180^{\circ}$ and $109^{\circ}$ in case of $F_{\mathrm{T}}$ and $F_{\mathrm{R}}$ phase, respectively. Further that it has shown comparatively small increment in $k_{\mathrm{p}}$ though the higher polarization reversal field is applied. This small increment may be due to reversal along hard axis (i.e. $90^{\circ}$ and $71^{\circ}$ in $F_{\mathrm{T}}$ and $F_{\mathrm{R}}$ phase, respectively) which has contributed less.

It was also observed that higher values of $k_{\mathrm{p}}$ were obtained at higher temperature at the same electric field applied. This clearly brings out the importance of temperature assisted poling. The $K_{\mathrm{p}}$ curve crosses at the abscissa which was the apparent coercieve field $\left(E_{\mathrm{CP}}\right)$. As the temperature increased, the $E_{\mathrm{CP}}$ values decreased. This was due to the effect of temperature on polarization reversal. The shapes of all the curves of $K_{\mathrm{p}}$ were asymmetric in nature and became more asymmetric as the temperature increased. The curve at $80^{\circ} \mathrm{C}$ was not exactly but nearly symmetric, because this was the poling temperature of the PSZT. In order to fully describe the effect of temperature over broad range of temperature and polarization reversal field, it will be convenient to plot a coercive field, $E_{\mathrm{CP}}$, as a function of temperature.

Figure 3 represents the effect of temperature, $E_{\mathrm{CP}}$, on polarization reversal. It was observed that in polarization reversal the rate of decrease of $E_{\mathrm{CP}}$ was different at different temperature ranges. In initial stage, from temperature $25-80^{\circ} \mathrm{C}$, the rate of decrease in $E_{\mathrm{CP}}$ was very sharp. After that, $E_{\mathrm{CP}}$ decreased slowly up to $100^{\circ} \mathrm{C}$ as compared to the above temperature range. Above that temperature the rate of decrease in $E_{\mathrm{CP}}$ was very small. The relationship between $E_{\mathrm{CP}}$ and temperature was not linear but is of exponential decay type.

Figure 4 represents the PR and FPR to original polarization of $k_{\mathrm{p}}$ at room temperature. The curve PR was the same as in figure 2 at room temperature. In FPR to original polarization direction, the values of $k_{\mathrm{p}}$ increased sharply in initial stage and passing through the abscissa again sharply it 


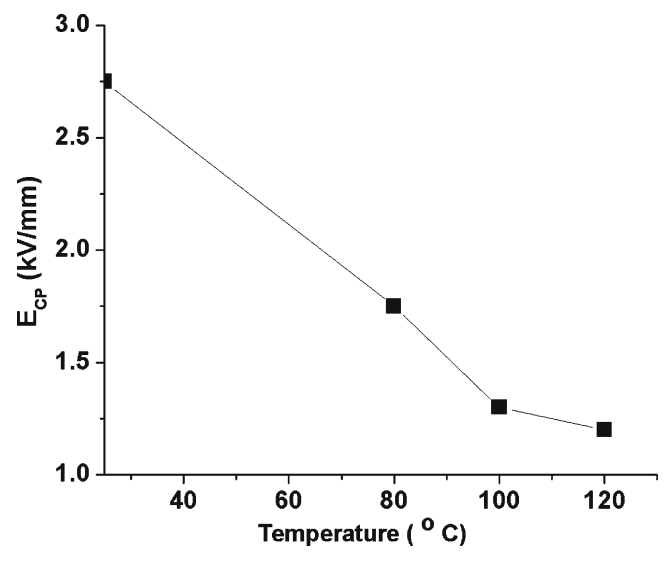

Figure 3. Apparent coercieve fields $\left(E_{\mathrm{cp}}\right)$ vs temperature.

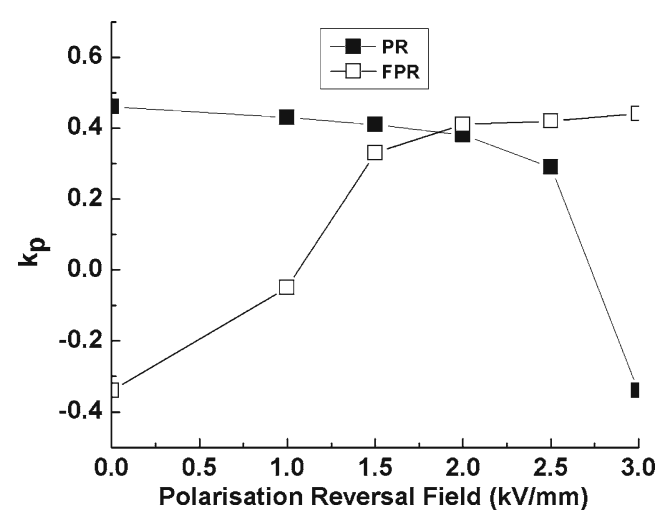

Figure 4. Polarization reversal and further polarization reversal of coupling coefficient $\left(k_{\mathrm{p}}\right)$.

increased up to $1.5 \mathrm{kV} / \mathrm{mm}$ polarization reversal field. Above that field, $k_{\mathrm{p}}$ slowly increased. The $k_{\mathrm{p}}$ value at $3 \mathrm{kV} / \mathrm{mm}$ of $\mathrm{PR}$ was greater than the value of FPR. The curves of PR and FPR were asymmetric to each other. The FPR crosses at the abscissa was also the apparent coercive field, $E_{\mathrm{CR}}$. The values of $E_{\mathrm{CP}}$ and $E_{\mathrm{CR}}$ were $2.75 \mathrm{kV} / \mathrm{mm}$ and $1.25 \mathrm{kV} / \mathrm{mm}$, respectively which were different from each other. The difference in $E_{\mathrm{CP}}$ and $E_{\mathrm{CR}}$ was because of internal field generated during aging. The space charge effect was responsible for internal field. The PR and FPR crossed each other at polarization reversal field, $1.80 \mathrm{kV} / \mathrm{mm}$, which was slightly lower than the average value of $E_{\mathrm{CP}}$ and $E_{\mathrm{CP}}$ $(2.75+1.25) / 2=2 \mathrm{kV} / \mathrm{mm}$.

Figure 5 represents the $\mathrm{PR}$ field vs $\left(T_{\mathrm{c}}-\right.$ texpt.) of $\mathrm{Sr}$ doped PZT for $25^{\circ} \mathrm{C}, 80^{\circ} \mathrm{C}, 100^{\circ} \mathrm{C}$ and $120^{\circ} \mathrm{C}$. It is seen that, with the increase in PR field, $\left(T_{\mathrm{c}}-t\right.$ expt.) increased and acquired maximum value and it subsequently decreased and stabilized thereafter. The increase in $\left(T_{\mathrm{c}}-\right.$ texpt.) at lower PR field is due to increase in $T_{\mathrm{c}}$ which indicates that the domain reversal was mainly responsible for the increase in $T_{\mathrm{c}}$. However, with the increase in PR field, domain reversal completes/reaches to a minimum value and at this point

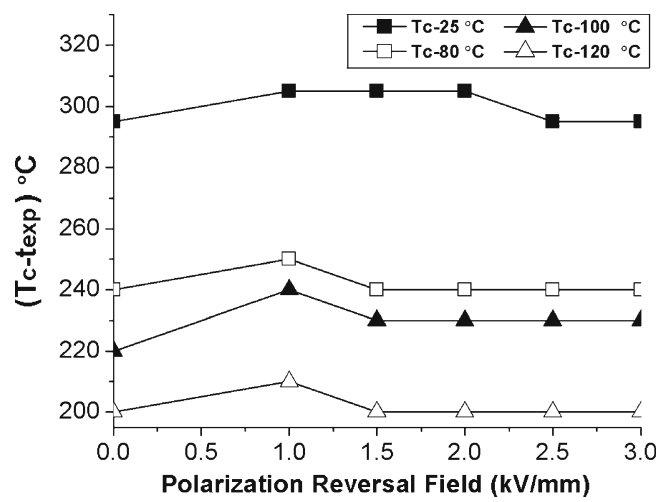

Figure 5. Polarization reversal field vs $\left(T_{\mathrm{c}}-t\right.$ expt $)$.

decreases in $\left(T_{\mathrm{c}}-\right.$ texpt.) can be seen. After this process, the domain starts aligning in opposite direction keeping $T_{\mathrm{c}}$ unchanged since because poling of piezoelectric ceramics does not have any effect on $T_{\mathrm{c}}$, whereas piezoelectric properties like $k_{\mathrm{p}}$ and $K_{3}^{T}$ increases as shown in figures 1 and 2 . At $25^{\circ} \mathrm{C}$, the $\left(T_{\mathrm{c}}-t\right.$ expt.) maxima was broadened since in PR domain reversal occurred at slow rate. With increased $t$ expt., maxima of ( $T_{\mathrm{c}}-t$ expt.) became sharp indicating PR domain reversal accelerating and showing lower PR field.

\section{Conclusions}

The effect of temperature on $K_{3}^{T}$ and $k_{\mathrm{p}}$ was observed in the polarization reversal of PSZT. As the temperature increased, $K_{3}^{T}$ and $k_{\mathrm{p}}$ in polarization reversal initially decreased and then again increased. The trend shown by dielectric constant indicates that at $25^{\circ} \mathrm{C}, 1.5 \mathrm{kV} / \mathrm{mm}$ field can be applied safely to this material without much compromising the properties. The shapes of $k_{\mathrm{p}}$ curves became more asymmetric as the temperature increased. D.c. field, $3.0 \mathrm{kV} / \mathrm{mm}$ and $100^{\circ} \mathrm{C}$ temperature, can be predicted as poling parameters from their effect on $k_{\mathrm{p}}$. In polarization reversal of $k_{\mathrm{p}}$, the values of $E_{\mathrm{CP}}$ decreased with increased temperature. After polarization reversal, observed values of $K_{3}^{T}$ at temperatures $80^{\circ} \mathrm{C}$, $100^{\circ} \mathrm{C}, 120^{\circ} \mathrm{C}$ were greater than that of $K_{3}^{T}$ values before polarization reversal. While $k_{\mathrm{p}}$ values at temperatures $100^{\circ} \mathrm{C}$ and $120^{\circ} \mathrm{C}$ were observed to be more than that of $K_{3}^{T}$ before polarization reversal. $E_{\mathrm{cp}}$ has shown exponential decay type of relationship with temperature.

\section{Acknowledgements}

The authors express their sincere gratitude to the Director, ARDE, for providing necessary support to carry out the research work. Thanks are also due to the members of PZT centre, ARDE, for their technical help in characterization of the material. 


\section{References}

Dimmler K, Parris M, Butler D, Eaton S, Pouligny B, Scott F and Ishibashi Y 1987 J. Appl. Phys. 615467

Jaffe B, Cook W R and Jaffe H 1971 Piezoelectric ceramics (New York: Academic Press)

Merz W J 1956 J. Appl. Phys. 27938

Nowotny J 1992 Electronics ceramics materials (USA: Trans Tech. Publication)
Okazaki K and Nagata K 1973 J. Am. Ceram. Soc. 5682

Wang T T, Herbert J M and Glass A M 1988 The applications of ferroelectric polymers (New York: Chapman and Hall)

Wenfung L, Wei C, Liu Y, Yu W, Lixue Z, Chao Z, Shengtao L and Xiaobing R 2006 J. Mater. Sci. Engg. A438-440 350

Yongjian Y, Jinbio T and Raj N 2001 J. Am. Ceram. Soc. 84 333 